\title{
NUEVAS TENDENCIAS EN LA EDUCACIÓN FÍSICA
}

\author{
Ma Luisa Zagalaz Sánchez \\ Rafael Moreno del Castillo \\ Javier Cachón Zagalaz \\ Universidad de Jaén
}

Durante la evolución que se ha producido en la Educación Física (EF) a lo largo de todo el siglo XX, existe una relación de influencia de la sociedad imperante en cada momento, hacia la formación del profesorado y hacia las demandas de esa sociedad.

Con frecuencia dicha influencia se plasma a través del marco legal que va reformando lo anteriormente establecido, de manera que, desde la Ley se recogen las necesidades sociales que el futuro profesional deberá atender, las funciones del maestro o del profesor en la sociedad, el status que se le otorga, etc... Con todo, se va moldeando un modelo de formación del profesorado que responde a los criterios políticos dominantes en cada situación (conservadores, liberales, socialistas...). Esta adecuación será la que trataremos de desarrollar en las líneas sucesivas, en las que intentaremos exponer las nuevas tendencias de la EF.

Las nuevas tendencias o corrientes actuales de EF, podemos dividirlas en dos partes:

- La primera, surge de los antecedentes más cercanos, en los siglos XVIII y XIX, que dan lugar a la configuración de algunas corrientes educativas alrededor del concepto de EF, denominadas por Vázquez $(1989,64)$ :

1) Educación físico-deportiva: el cuerpo acrobático.

2) Educación psicomotriz: el cuerpo pensante.

3) Expresión corporal: el cuerpo comunicante.

A estas tres tendencias podemos sumar una cuarta, la sociomotricidad, definida por Parlebás (1974) como, una motricidad en relación con los compañeros y desarrollada principalmente en los juegos.

- La segunda parte incluye otras corrientes que, por su incidencia social, recreativa y, por supuesto, educativa, no debemos dejar de conocer. Dichas corrientes son:

1. Corriente Centroeuropea.

2. Corriente de las Habilidades Motrices Básicas (USA).

3. Corriente Psicomotriz.

4. Corriente de Educación Física para alumnos con necesidades educativas especiales.

5. Corriente de Expresión y Comunicación.

6. Corriente Multideportiva. 
7. Corriente Alternativa.

8. Corriente de Actividades en la Naturaleza.

9. Corriente de Actividad Física y Salud.

10. Corriente de Actividad Física en mayores.

11. Corriente de Actividad Física y Turismo.

12. Corriente de Culto al cuerpo.

13. La EF en la Transversalidad.

Nos detendremos brevemente en cada una de ellas, comenzando por el primer apartado.

\section{Corrientes de la educación física}

\subsection{La educación físico-deportiva: el cuerpo acrobático}

En esta corriente se plantean las diferencias y similitudes entre EF y Deporte a la hora de desarrollar los criterios educativos en nuestra materia.

Comienza cuando Hèbert, recupera el término Educación Física como más comprensivo de la educación corporal que la simple gimnástica, y evoluciona hasta que mucho más tarde, Vázquez (1989), habla del afianzamiento de la expresión Educación Física sobre la de Gimnasia, pasando por los movimientos europeos y sus influencias recíprocas que fructificaron, hacia mediados de siglo XX, en una EF metódica, analítica y moralista en cuanto a los efectos provocados por las metodologías empleadas para su enseñanza.

Las clases se imparten a base de "lecciones", con ejercicios sometidos a evolución y control mediante "ejercicios-tests" que, permitirán al profesor un conocimiento rápido y riguroso del proceso de enseñanza. La práctica se resuelve por medio de ejercicios construidos por el profesorado o por el propio alumnado que van de lo simple a lo complejo. El procedimiento pedagógico más utilizado es la demostración.

Esta forma de entender la EF no goza del interés de los escolares, por lo que cae en un creciente desprestigio. Entonces se incorpora el deporte a la enseñanza y, posteriormente, se añaden una parte de la educación psicomotriz, de la expresión corporal y de la recreación.

Respecto al Deporte, fueron dos hechos fundamentales, uno en el siglo XIX y otro en el siglo XX, los determinantes de su utilización en la educación. El primero, fue obra de Thomas Arnold al introducir los juegos deportivos en los colegios ingleses y, el segundo, se debió al Barón Pièrre de Coubertín y su instauración de los Juegos Olímpicos contemporáneos, cuya influencia social se deja notar en la educación de la época.

El Deporte ha sido en los tiempos recientes y hoy mismo, más una preocupación política y económica, que educativa. Esta situación se ve agravada, en parte, porque algunos profesionales del deporte se han formado tradicionalmente en ausencia de toda preparación pedagógica y buscan en el deporte escolar el rendimiento y la competición.

Hoy sabemos que no es este el sentido del deporte escolar, muy al contrario, se trata de educar a través del deporte, como si éste fuese la cima de la EF; se considera el 
deporte como sistema educativo, para alcanzar una formación completa, física, moral y social y, a la vez, extender el gusto por estas actividades más allá de la edad escolar.

Por este motivo recogemos aquí diferentes tipos de deporte, que Blázquez (1993) clasifica en:

- Deporte recreativo, el practicado por placer y diversión, sin ninguna intención de competir o superar a un adversario.

- Deporte competitivo, el ejercido con la intención de vencer a un adversario o de superarse a uno mismo.

- Deporte educativo, el que tiene como pretensión fundamental colaborar al desarrollo armónico y potenciar los valores del individuo.

Por último, como resultado entre el dilema terminológico y conceptual sobre Educación Física-Deporte, obtenemos la denominación actividad física, que engloba ambos términos y reúne características de recreación, estética corporal, socialización y salud, como objetivos a conseguir a largo plazo, mucho más allá de las etapas de enseñanza obligatoria.

\subsection{La educación psicomotriz: el cuerpo pensante}

La segunda corriente a que se refiere Vázquez es la educación psicomotriz.

El término psicomotricidad proviene de la psiquiatría y la psicología y es, ciertamente, contradictorio; por un lado utiliza un nombre nuevo para algo que ya existía (conocido es que en todo movimiento participan estructuras mentales y físicas), por otro, alude a la globalidad de la persona, a la realidad psicosomática -hecho este muy importante para la EF-, con un término dualista en sí mismo.

La educación psicomotriz comienza a difundirse en Francia, a partir de las décadas de los años cincuenta y sesenta del pasado siglo, mientras que en nuestro país, se desarrolla aproximadamente en la década de los setenta. Se concibe como una educación dirigida no ya al cuerpo como entidad meramente biológica, sino psicosomática, en la que las estructuras motrices se desarrollan en interacción constante entre el yo y el medio, ya sea físico o social.

La psicomotricidad se relaciona con la reeducación motriz, acercándonos a cuestiones de EF para alumnos con necesidades educativas especiales, y directamente con la EF, desde el momento que se utilizan técnicas de prevención para evitar la reeducación, dichas técnicas son:

a) el método psicocinético de Jean le Boulch, definido por el autor como un método general de educación que utiliza como material pedagógico el movimiento humano en todas sus formas.

b) la educación corporal de Louis Picq y Pièrre Vayer, quienes definen la psicomotricidad como una acción pedagógica y psicológica que utiliza los medios de la EF con el fin de normalizar o mejorar el comportamiento del niño.

c) la educación vivenciada de André Lapièrre y Bernard Aucounturier, para quienes, la psicomotricidad, rebasa los límites de una técnica especializada convirtiéndose en el punto de partida de toda educación. Los aprendizajes escolares son vividos por el niño como una imposición arbitraria del adulto, y para evitar esto, los autores centran su trabajo en la educación vivenciada, donde el niño participa en su propia educación. 
Otra interpretación diferenciadora es la que realiza Contreras (1998), cuando afirma que el enfoque de Le Boulch, tiene en el movimiento su objetivo final, mientras que los de Picq, Vayer, Lapièrre y Aucounturier, utilizan el movimiento para conseguir otro tipo de objetivos educativos.

\subsection{La expresión corporal: el cuerpo comunicante.}

Por último, entre las corrientes planteadas por Vázquez, nos queda la expresión corporal: el cuerpo comunicante, que surge para buscar el equilibrio psico-físico del alumnado y se convertirá, como veremos, en una tendencia recreativa.

En un principio, la falta de concreción en los contenidos de esta tendencia hace que en ella se den cita de manera convulsa las prácticas más variopintas: desde actividades extraescolares relacionadas con la expresión, hasta la danza, la psicomotricidad, el mimo, las técnicas de expresión corporal, el teatro..., todo dependía del conocimiento e implicación del profesorado.

Actualmente es un núcleo de contenidos de la enseñanza primaria, secundaria y bachillerato, en el que se trabajan desde las habilidades perceptivomotrices hasta las más complicadas coreografías, pasando por los cuentos motores, los bailes de salón, el aerobic, step, etc... de alguna manera sistematizadas, adaptadas a las diferentes edades y entornos, y que gustan mucho a nuestros estudiantes. No obstante podemos considerar que existen cuatro modalidades de expresión corporal:

- La expresión corporal de espectáculo o escénica, en la que el acento recae sobre la función comunicativa, que consiste en la transmisión al público de un mensaje en el que deben estar implicados un personaje con sus ideas y sentimientos y una forma gestual apropiada (técnica expresiva).

- La expresión corporal pedagógica, desarrollada en el mundo escolar, que forzosamente hará referencia a las teorías psicopedagógicas predominantes y al marco institucional en el que se desarrollan. Orientada a la concienciación y máxima disponibilidad del niño y la niña, así como a los aprendizajes posteriores.

- La expresión corporal psicoanalítica, ligada a la enorme variedad de psicoterapias en uso. Pretende ayudar a profundizar y expresar lo que pasa en el fondo de uno mismo. Podríamos considerarla terapéutica.

- La expresión corporal metafísica, denominada así en el sentido literal de experiencia, que pretende llegar más allá de lo físico para volver a los supuestos orígenes o trascender, como superación de la finitud.

La aplicación práctica de la expresión corporal en EF, basándonos directamente en los planteamientos de la LOGSE, se compone de:

- Educación postural e imagen corporal.

- Expresión y comunicación no discursiva: Lenguaje corporal y gesto.

- Dominio del espacio-tiempo.

- Danza/Baile.

- Teatro evolutivo (Juego simbólico; Juego de Roles; Juego dramático; Dramática creativa; Creación colectiva y montaje de textos).

- Mimo. 


\subsection{La sociomotricidad de P. Parlebás}

En este conjunto de corrientes iniciales de la EF, se incluye en último lugar, como hemos apuntado, la sociomotricidad.

Partiendo de la psicomotricidad, cuyo método tiene el mérito de haber centrado la mirada, no en el movimiento, sino en el ser que se mueve, Parlebás comprueba que es un concepto insuficiente, ya que alude a aspectos individuales del movimiento, a una motricidad aislada cuyo punto de referencia fundamental es colectivo; por tanto, la motricidad individual se ve afectada constantemente por la motricidad de los adversarios y de los compañeros de juegos, así como por el entorno en que se desarrolla la actividad física (factores climatológicos, espectadores, entrenadores, etc...), configurando todos ellos la incertidumbre en la acción motriz, es por esos motivos una motricidad en relación, una motricidad social, a la que el autor define con el término de Sociomotricidad.

Vistas las cuatro tendencias que se derivan de los antecedentes de la EF, pasaremos ahora a revisar las tendencias más actuales.

\section{OTRAS CORRIENTES DE EDUCACIÓN FÍSICA Y DEPORTES.}

La EF puede modificar la conducta motriz y la conducta del individuo, es decir su personalidad, crear mejores hábitos de vida y completar su proceso de relación, por lo que tiene un amplio marco de actuación en todos los ámbitos de la vida del hombre. A partir de estas premisas consideramos las siguientes corrientes o tendencias de la EF.

\subsection{Corriente centroeuropea}

La corriente centroeuropea hace su aportación a la generalización de habilidades, siendo los autores más relevantes Groll, Pock, Koch, Schmidt, Mittervauer, A.L.E.F.U.C.L. (Bélgica), Reclá, Burger, etc... Se compone de tres líneas:

a) Gimnasia Escolar Austriaca. Nacida de las ideas del método natural de la gimnasia francesa, del método lúdico-deportivo inglés, de la vida al aire libre, de la gimnasia pedagógica, del turnkunst y de la gimnasia moderna de R. Bode. Sus creadores son, Karl Gaulhofer y Margarette Streicher. Fue introducida en España por G. Schmidt, y actualmente se la conoce por "Educación Física Escolar". Incluye ejercicios de control postural y formación corporal, ritmo y danza. Actividades en la naturaleza y muchos juegos, por tanto despierta el interés del alumnado.

b) La Asociación de Licenciados en Educación Física de la Universidad Católica de Lovaina (A.L.E.F.U.C.L.), también conocida, como corriente de las habilidades genéricas, que persigue objetivos a largo plazo sin buscar la técnica perfecta, sino la mejor aplicación a cualquier situación. Su objetivo prioritario es el desarrollo y dominio de las conductas motrices, aludiendo al trabajo de las cualidades físicas, aspectos psicomotrices (esquema corporal, percepción espacial, percepción temporal); y psicosociales (trabajo en grupo, cooperación).

c) La Escuela Alemana. Configura la tercera línea de esta corriente siendo de propuestas muy similares a la A.L.E.F.U.C.L.

De la corriente centroeuropea se deriva un modelo educativo que denominamos Tradicional. Este modelo parte de la Escuela Central de Educación Física de Toledo, 
influenciado por la Gimnasia Sueca. Se compone de Gimnasia, como base del modelo y de Juegos, que utiliza como medios auxiliares e, incluye los Deportes, destacando el atletismo, la natación y el baloncesto, siempre como medios de la EF.

\subsection{Corriente de las habilidades motrices básicas (USA)}

Su aportación se dirige a las habilidades básicas y entre sus representantes destacamos a Getman, Kephart, Dolman, Delacato, Oliver, Kiphard, Cratty, Mosston, Fleishman, Bruner, Conolly, McGrew, Guilford, McClenaghan, Gallahue, Lawther, Barry, Wickstrom, etc..., y puede tener incidencia en el ámbito de la EF para alumnos con necesidades educativas especiales.

Las aportaciones de estos autores establecen cuatro enfoques, el primero perceptivo-motriz, en el que la capacidad perceptiva es la base de cualquier aprendizaje; el segundo, de organización neurológica, donde se afirma que el niño pasa por etapas de desarrollo iguales a las que ha pasado el ser humano desde sus comienzos como animal acuático; el tercero, dinámico, mediante el que con una actividad motriz positiva pueden modificarse facetas de la personalidad infantil; $y$, el cuarto, a través de los modelos cognoscitivos, que desarrollan funciones intelectuales y operaciones académicas con la ayuda de experiencias de movimiento.

De esta corriente surgen dos modelos, el Integrador y el Conductual, el primero aparece en España a principios de los años setenta, coincidiendo con la promulgación de la Ley General de Educación (1970), que alude en su Art. 16 al desarrollo de las capacidades físico-deportivas en el período de formación educativa básica. Como consecuencia se programa una Guía Didáctica para EF en Educación General Básica, creándose en este nivel de la enseñanza un área de Expresión Dinámica y otra de Educación Físico-Deportiva para la $1^{\underline{a}}$ y $2^{a}$ etapas respectivamente. El área de Expresión Dinámica, recoge por primera vez la educación por el movimiento, el ritmo, expresión corporal, mimo, dramatización, juegos, gimnasia, música, deportes, etc..., es decir, se apoya en el Modelo Psicomotor, que veremos a continuación. Contemplándose por primera vez la atención a edades más tempranas.

Este proceso integrador se sintió también en los centros de EF, pasando todos a unificarse en torno al INEF de Madrid, creado en virtud de la Ley de EF de 1961, aunque su puesta en funcionamiento no se produce hasta 1967 (Zagalaz, 1999).

Se imparten en España infinidad de cursos por especialistas extranjeros, entre los que podemos citar a Le Boulch, Picq, Vayer, Seybold, Beckman,o Schmidt, lo cual produce un intento de acercamiento a otros países y, en definitiva, una integración en el sistema.

Con respecto al modelo Conductual, es una prolongación del modelo psicomotor que se introduce en España en los años ochenta, siendo sus máximos defensores, Cratty, Mosston y Humphrey, quienes se basan en los Modelos cognoscitivos que a su vez están sostenidos por la Teoría de Piaget. En el currículo de educación primaria, se aplica mediante el bloque de contenidos, el cuerpo: habilidades y destrezas, e intenta el afianzamiento de las habilidades perceptivo-motrices y las básicas, para iniciar el desarrollo de las habilidades genéricas y, posteriormente, la especialización.

\subsection{Corriente Psicomotriz}

Esta corriente corresponde a la que Vázquez denomina "educación psicomotriz: el cuerpo pensante", ya expuesta, que se desarrolla a través del modelo Psicomotor. 
Este modelo es apoyado por numerosos y conocidos autores, a los que ya hemos hecho referencia, Picq, Vayer, Lapièrre o Aucounturier, que a partir de la revolución pedagógica que surge en Francia en los años sesenta, sostienen la relación entre la motricidad y los trastornos del comportamiento, entre los aspectos perceptivos-motrices y los aprendizajes escolares. Le Boulch aporta su método psicocinético, descrito con anterioridad y, en consecuencia, los Diseños Curriculares de la LOGSE, apoyan sus contenidos casi totalmente en este modelo.

\subsection{Corriente de Educación Física para alumnos con necesidades educativas especiales}

Podríamos considerar esta corriente como una continuación de la psicomotriz que acabamos de exponer, sobre todo a la vista de los planteamientos establecidos por los diferentes autores que la sustentan. Se trabaja por medio de una Didáctica de la EF adaptada que pone su atención en el tratamiento de las Necesidades Educativas Especiales (NEE) en la materia, las cuales se establecen atendiendo a los mecanismos implicados en el aprendizaje motor, que podemos dividir en:

a) Deficiencias sensoriales (auditivas, visuales, trastornos del lenguaje o de otros sentidos).

b) Deficiencias psíquicas (cuyo criterio clasificatorio es el coeficiente intelectual, siendo ligeros los que lo tienen en el límite de 70 puntos; medianos, entre 40 y 60; severos, entre 20 y 40; y profundos, inferior a 20 puntos, así como otras alteraciones tales como la esquizofrenia, psicoautismo, trastornos de la conducta o problemas de socialización: anorexia y bulimia).

c) Deficiencias físico-motrices (deformaciones ortopédicas, lesión medular, amputaciones, poliomielitis, espina bífida, parálisis cerebral y epilepsia y por otra parte, accidentes vasculares, traumatismo craneal, distrofia muscular, artritis o reumatismo, asma, obesidad, etc.).

Los criterios y procedimientos para la atención y tratamiento de las NEE en EF se basarán en los principios de adaptación curricular y en la detección de dichas necesidades, mediante la evaluación inicial. Siguiendo, a continuación, un proceso de adaptación a las tareas motrices consistente en la evaluación de las características particulares para el aprendizaje, análisis y adaptación de la tarea, aplicación y seguimiento, adaptaciones metodológicas y organizativas, adaptaciones del entorno y el material, y por último, adaptaciones de la tarea motriz.

En el Congreso Mundial de la AFA (Actividad Física Adaptada) de 1998, ésta se define como "un cuerpo de conocimiento disciplinar dirigido a la identificación y solución de las diferencias individuales en la actividad física. Es una profesión de prestación de servicio y un cuerpo académico de estudio que apoya una actitud de aceptación de las diferencias individuales, aboga por mejorar el acceso a estilos de vida y al deporte, y promueve la innovación y la cooperación en la prestación de servicios y la adaptación de las normativas".

La actividad física adaptada incluye la EF, el deporte, la recreación, la danza, las artes creativas, la medicina, la nutrición y la rehabilitación.

Por último, si consideramos la gran trascendencia de eventos deportivos como las paraolimpiadas, podemos entender la importancia de esta corriente que para su puesta en práctica se apoya en los diferentes modelos de aplicación, dando origen al modelo Adaptado. 


\subsection{Corriente de expresión y comunicación}

Coincide plenamente con la que Vázquez denomina "La expresión corporal: el cuerpo comunicante", ya descrita, cuyo desarrollo se produce a través del modelo Rítmico que surge de la aportación de la música al movimiento e incluye la Gimnasia Rítmica, el Aerobic, la Gimnasia Jazz, los bailes populares y los bailes de salón.

Se considera un modelo educativo, no sólo por el auge que ha adquirido en los niveles superiores de Educación Primaria, en Educación Secundaria y en Bachillerato, sino porque se acerca enormemente a los sistemas de expresión y comunicación gestual, así como al desarrollo de las funciones de relación (sociomotricidad) que, como objetivos afectivos, son tan importantes en las edades de formación y posteriores.

\subsection{Corriente multideportiva}

Contiene y desarrolla las habilidades específicas. Entre sus representantes, podemos citar a Sánchez Bañuelos, Blázquez, Moral, Cantó, Hernández Manchón, Seirullo, Pila, Serra o Parlebás, que establecen la enseñanza multideportiva en tres categorías: deportes individuales, deportes de adversario (con contacto y sin contacto); y deportes colectivos. Sostienen que para llegar a la adquisición de las habilidades específicas y especializadas, hay que desarrollar, a priori, las habilidades perceptivas, básicas y genéricas, no como se venía haciendo a partir de la participación específica deportiva en cualquier edad y desde el propio deporte. Apoyan la multidisciplinariedad deportiva en las primeras edades hasta determinar en cual se especializarán, por tanto, están muy cercanos a los planteamientos deportivos escolares americanos.

La cara deportiva de esta corriente procede del deporte educativo británico, con la significativa particularidad de que en el resto de Europa éste se introduce en la educación después de arraigarse en la sociedad. Por tanto, el deporte al acceder a la EF en Europa y en España, lleva consigo todo el lastre que supone la contaminación política (exaltación nacionalista y propaganda nacional e internacional de los gobiernos), a la que posteriormente se unirá la económica (publicidad, intereses económicos multinacionales, consumismo, superprofesionalismo, etc...), y a la que, desgraciadamente en estos últimos años, habría que añadir la violencia.

Pero no son estos los únicos lastres con los que el deporte accede a la EF en el Continente, además trae consigo los fines competitivos de rendimiento $y$, sobre todo, los métodos de enseñanza conductistas, analíticos, repetitivos, directivos y centrados en la materia y en el profesorado y no en el alumnado. Las prácticas "deportivistas" de la EF son además sexistas y excluyentes, discriminan a las chicas con respecto a los chicos y a los que poseen "gusto por el deporte, más capacidad motriz" con respecto a los menos capacitados motrizmente y menos atraídos por el deporte (Lozano, 1996, 39).

Así las cosas, no tardarán en levantarse voces en contra de esta manera de introducir el deporte en el currículum de la EF escolar. Transcurre el tiempo y algunas modificaciones educativas se van consiguiendo al respecto, hasta que la LOGSE se pronuncia sobre el deporte en educación Primaria diciendo el DCB que: "La práctica deportiva, sin embargo, tal como es socialmente apreciada, corresponde a planteamientos competitivos, selectivos y restringidos a una sola especialidad, que no siempre son compatibles con las intenciones educativas del currículo. Para constituir un hecho educativo, el deporte ha de tener un carácter abierto, sin que la participación se supedite a las características de sexo, niveles de habilidad u otros criterios de dis- 
criminación; y debe, así mismo realizarse con fines educativos (...) y no con la finalidad de obtener un resultado en la actividad competitiva", MEC (1992, 15).

Después de esta declaración de principios, en los contenidos del Decreto que desarrolla esta ley no aparece la palabra deporte, que es sustituida por juego. Ya sabemos que el deporte es un juego, pero un juego que alcanza su máximo esplendor cuando se convierte en deporte y, eso es precisamente lo que quieren los escolares.

Por estas razones, hemos de ser capaces de desarrollar al unísono en los jóvenes, conceptos de competición, inherentes al ser humano y, de colaboración, y así podremos introducir el deporte en la escuela, usándolo como recurso didáctico o fin en sí mismo.

En este sentido coincidimos con Arnold (1991, 39), cuando dice que "la razón por la cual, se da mayor importancia al deporte, de entre todas las actividades físicas, consiste en que, desprovisto de finalidades propias, pero ligado a la idea de progresar, se presta perfectamente a la educación de los jóvenes, dado que implica la confrontación, la competición y la colaboración. A través del deporte surge un comportamiento y un estado de espíritu ejemplar, su alcance educativo puede ser considerable".

En la misma línea se sitúa Diem $(1996,118)$ al afirmar que "no hay educación sin deporte, no hay belleza sin deporte; sólo el hombre educado físicamente es verdaderamente educado, sólo él es en efecto hermoso, y lo hermoso es idéntico a lo bueno".

El deporte enseñado correctamente, presenta otra característica educativa, permite la elevación de la autoestima en el alumno, y en este sentido, Bergson, citado por Gillet (1971), afirma: "Lo que más estimo de los deportes es la confianza en sí mismo que procuran al hombre que los cultiva".

Por tanto, la corriente de EF que lo recoge, está en auge y, los educadores, entrenadores, monitores, etc..., que realizan su actividad con niños, niñas y jóvenes, deben conocer y valorar las inmensas posibilidades educativas que presenta.

De esta corriente parte el modelo Multideportivo, como continuación al psicomotor y pretende el desarrollo de las habilidades específicas. Busca el desarrollo máximo de las cualidades físicas del individuo en función de las pruebas deportivas, se apoya en el Modelo conductual, mediante el cual el alumnado conoce y domina dichas habilidades, comenzando su especialización deportiva. Su planteamiento se hace a través del juego popular o predeportivo con lo que la enseñanza en edad escolar consigue sus funciones de aprendizaje y comunicación.

Pero si queremos entrar en un debate más profundo sobre las ventajas o inconvenientes de su inclusión en el currículum educativo, que nos conducirá al modelo Humanista, podemos comenzar con la cita de Huxley (1969, 187-188), en Zagalaz y Cachón (1999): "El deporte puede ser o bien una preparación para la guerra o en cierta medida, un sustituto de ésta; un adiestramiento de belicistas potenciales o de pacifistas en potencia; una influencia educativa para la formación de militaristas o de hombres que estén dispuestos y que sean capaces de aplicar los principios del pacifismo en cada actividad de la vida".

Recordemos que el sistema educativo español, expresa entre sus fines, la formación para la paz, la cooperación, y la solidaridad entre los pueblos. En la intención de suscitar el debate entre el deporte para la guerra o deporte para la paz, deporte competitivo y deporte educativo, deporte extraescolar y deporte escolar, entre el deporte 
de espectador y el deporte de acción, se han seleccionado estos tres objetivos de la normativa oficial sobre educación, por entender que a través del deporte, de la índole que sea, es factible educar y como, evidentemente, el deporte forma parte de currículum escolar, como contenido específico y como medio de la educación, es importante hacer una amplia reflexión acerca de sus valores.

De entre los tres objetivos señalados, parece que la cooperación está más relacionada con el mundo del deporte, sobre todo en aquellos juegos competitivos en los que se participa por equipos y se hace necesaria para su realización la unidad del conjunto y la colaboración entre sus integrantes. Sin embargo, si pretendemos utilizar el deporte como medio educativo, hemos de considerar la importancia de la solidaridad, que requerirá del alumnado, no sólo, la cooperación con sus compañeros o compañeras de equipo, sino también, el tener en cuenta la realidad, emociones y circunstancias externas de los componentes del conjunto al que se enfrenten. Este sistema, dará como resultado, la educación para la paz que, como eje transversal, se contempla en la actual Ley de Educación y su desarrollo posterior.

Que existe violencia en el deporte es evidente, agresiones físicas y verbales que se producen entre los jugadores y jugadoras de todos los deportes y todas las edades, ocasionando, a veces, graves lesiones físicas y/o emocionales, pero además los espectadores, seguidores o contrarios del equipo correspondiente, padres y madres de alumnos o alumnas que están participando en alguna competición, entrenadores y entrenadoras de los equipos, también observan comportamientos violentos, dentro y fuera de los estadios y pabellones donde se desarrollan las competiciones. Existe además otro tipo de violencia que casi nunca trasciende y que es importante conocer a la hora de realizar un planteamiento educativo alrededor del deporte, es el dopaje, sin duda el máximo riesgo de la competición de alto rendimiento, que puede trascender a niveles inferiores del mundo del deporte.

Por estos motivos hay que realizar un intenso trabajo al objeto de conseguir que la solidaridad que, puede ser la clave para acabar con la violencia en el deporte, se desarrolle e inculque a alumnos y alumnas, en la certeza de la importancia que tienen todas las personas, porque nos necesitamos mutuamente $y$, en el caso de la competición deportiva, sería muy difícil culminarla si no tuviéramos un equipo contrario con el que enfrentarnos o unos compañeros con los que colaborar.

El deporte implica esfuerzo y se realiza para divertirse, pero además, está sujeto a unas reglas, de cuyo cumplimiento u omisión se derivará el pasar o no la frontera de la paz hacia la guerra. Porque, si según Oldenhove (1992): "Los jóvenes aprueban apasionadamente el deporte", deben aprender que los derechos de los jugadores de un equipo, acaban donde empiezan los del equipo contrario. Si somos capaces de inculcar a nuestros alumnos este concepto de respeto hacia las normas, adornado de características de colaboración con sus compañeros y solidaridad con sus contrincantes, habremos conseguido avanzar hacia los principios educativos del deporte que tanto preocupan a la sociedad actual, pero para los que no articula ningún remedio práctico, porque el intentar excluirlo de los currículos educativos sólo puede conducir a su desconocimiento o a la práctica en escuelas municipales o clubes, donde su aprendizaje adolece, por lo general, del carácter educativo que le es propio.

El deporte constituye un producto de elaboración social dentro de la cultura en la que está inmerso, su carácter histórico le ha condicionado a los intereses de las distintas clases sociales y políticas, pero como las personas viven en esas sociedades, y 
en sus comportamientos innatos aparece el afán por la lucha, el juego, la confrontación, la colaboración, etc..., habrá que buscar el sistema que permita utilizarlo como elemento educativo, cuya potencialidad es evidente $y$, dependerá, en gran proporción, de las características personales y docentes del profesorado, la familia, el centro escolar y el sistema educativo legalmente establecido, siendo el profesor o la profesora, los que han de liberar al deporte de las cohesiones a otros ámbitos incompatibles con su carácter educativo, desde la práctica crítica y reflexiva que lo convierta en un instrumento para la paz y nunca un elemento violento o belicista.

\subsection{Corriente alternativa}

Durante las décadas de los ochenta y de los noventa, del pasado siglo, irrumpen en la escena de la actividad física y deportiva una serie de prácticas físicas cuyo epicentro se sitúa, casi siempre, en los Estados Unidos, concretamente en la costa californiana, y se extienden rápidamente por el mundo occidental.

Estas actividades surgen como consecuencia de la degeneración de los deportes tradicionales de dimensión internacional, que no acaban de adaptarse a los cambios de la vanguardia social y se presentan como alternativa a la oferta existente con el respaldo de unas características y valores propios de la postmodernidad de cuyos rasgos participan, en cuanto que en ellos los valores femeninos están en alza; forman parte de un proceso de personalización; la información, posee gran importancia; están inmersas en una nueva conciencia ecológica, flexible, cordial y con sentido del humor; y sus practicantes tienen rasgos del hombre y la mujer a los que les gusta la complejidad, la incertidumbre, la autoorganización, el riesgo y el uso creativo del azar, son, por tanto, denominados de aventura, de riesgo, etc...

Al citado movimiento podrían pertenecer actividades tan variadas como las denominadas novedosas sin riesgo (el Aerobic, el Physical Fitness, el Body-building, el rowing, y un largo etcétera). Y otras que se denominan deportes californianos, a los que les une ser actividades deslizantes por tierra, mar y aire (mountain bike, skate; surf, rafting; o puenting, parapente, respectivamente).

En todas, además, se utiliza el ideal de "cuerpo postmoderno" caracterizado por ser un producto de consumo (prendas deportivas, productos dietéticos, etc...), medio de combate ante los males de la civilización (estrés, sedentarismo, etc...), remedio contra la inseguridad, la soledad, la angustia y vehículo para múltiples experiencias. A pesar de su común origen contestatario y alternativo, su trayectoria muestra que sucumben a la todopoderosa maquinaria económica y política que los absorbe sin dificultad, a través de la competición institucionalizada, la comercialización internacional de material, etc...

Postmodernas o no, lo cierto es que este tipo de actividades fueron incluyéndose de forma masiva en el currículum de la EF. Algunas, lógicamente no tenían cabida en el marco escolar, pero todas las que fueron susceptibles de ello han ido engrosando la lista de los "juegos y deportes alternativos", tal fue el nombre que como contenido de la disciplina se les asignó. En este conjunto se incluyeron, el disco volador, las cometas, los pompones, el bádminton, el aerobic, el patinaje, los zancos, indiacas, diábolos, boomerang, la orientación, el voley-playa..., pero pronto les ocurrió lo mismo que a las actividades originales en el ámbito extraescolar, fueron engullidas por la propia dinámica escolar de manera que, por ejemplo, el material llegaba al colegio a través de las redes comerciales habituales y, quizá lo más grave, la aplica- 
ción reglada y la metodología empleada hicieron que pasaran de ser juegos "alternativos" a juegos "novedosos" (García; Miguel; Abadía, 1992).

Esta corriente se desarrolla, junto a las siguientes, a través del modelo Constructivista y, está, configurada por las nuevas modalidades de la actividad física.

\subsection{Corriente de actividades en la naturaleza}

Disfrutar en y de la Naturaleza, ha sido habitual para el hombre desde siempre, sin embargo estas actividades se han alejado del currículum educativo a pesar de estar recogidas en la LOGSE, para Enseñanza Secundaria, como un núcleo de contenidos.

En los últimos años del siglo XX, las actividades en la Naturaleza, quizá por el alza en que se encuentran los aspectos ecologistas de la sociedad, aparecen con fuerza como componentes del tiempo libre, ya sea para realizar algún tipo de deporte: golf, natación, esquí, piragüismo, vela, windsurf, escalada, parapente, etc..., como para el desarrollo de marchas, acampadas, juegos de campamentos, cabuyería, orientación, supervivencia, senderismo (a pie, a caballo, en bicicleta), que van a acercar a los participantes a las zonas más desconocidas y alejadas de los núcleos urbanos, haciendo surgir otra actividad, el turismo rural y ecológico, que se ha dado en llamar turismo activo.

Los campamentos, se convierten en el sitio ideal para desarrollar este tipo de actividad, bien como contenido de la EF reglada, bien como actividad extraescolar. Dicho espacio temporal, adquiere además otros aspectos relacionados con la salud y algunos parámetros medio ambientales. Su objetivo es educar a los niños y jóvenes para disfrutar de su tiempo de ocio, considerando que éste se puede definir siguiendo a Dumasedier y Hennion (1960), como, "el conjunto de ocupaciones por las que el individuo se da a su placer, ya para descansar, ya para divertirse, ya para desarrollar su información o formación desinteresadamente y su participación social voluntaria, después de su libre acción de las obligaciones profesionales, familiares y sociales"... No olvidemos que "Para que el ocio sea el equilibrio de la persona tiene que cumplir tres funciones: descansar, divertir y desarrollar o enriquecer la personalidad".

La corriente de actividades en la naturaleza ha tomado fuerza a pesar de la oposición del profesorado a realizar este tipo de tareas, por el riesgo de accidentes u otro tipo de contingencia que conllevan.

Por otra parte, como es indiscutible el impacto ambiental de las actividades que se desarrollan en la naturaleza, es necesario arbitrar un sistema que permita su conocimiento y adecuación, tanto al medio, como a los usuarios. Para ello, lo primero será diseñar las estrategias para la consolidación de la demanda de deportes en la naturaleza, mediante un programa de dinamización de bases, que parte de su integración en el sistema educativo y en la política municipal deportiva y federativa, y que puede llevarse a cabo a través del currículum de los programas de salud y prevención de drogodependencias, de los materiales didácticos, del deporte escolar, de las actividades extraescolares, de la Universidad, de la creación de escuelas deportivas de aventura, y de campamentos, todo ello, estableciendo acuerdos y convenios de colaboración con diferentes entidades, formando y especializando técnicos y por último, consolidando el turismo deportivo o actividad física no tradicional. Dicha consolidación requiere un plan de actuación a nivel local, provincial, nacional e internacional.

Su puesta en práctica se hará mediante los modelos Constructivista y Cultural. 


\subsection{Corriente de actividad física y salud}

Otra de las corrientes que irrumpe con fuerza es la que recoge contenidos de actividad física y salud, considerada desde la perspectiva de la práctica regular de actividades físicas como hábito de vida saludable, algo científicamente comprobado y socialmente aceptado, téngase en cuenta que en los últimos años se ha demostrado que la vida sedentaria aumenta el riesgo de morbilidad (efectos de una enfermedad en una población) y mortalidad.

La práctica de deportes o actividades físicas, cada vez más asidua entre la población, se produce por causas diferentes que, en la mayoría de los casos, tienen su origen en razones personales originadas por el estilo de vida y la búsqueda de la salud integral (física, psíquica y social), aspectos muy importantes para comprender la conducta de los seres humanos en relación con la salud.

La práctica asidua de actividad física va descendiendo con la edad y, es por ello, que los programas de actividad física-salud destinados a la población adulta, deben constituirse y considerarse como una opción válida de ejercicio físico regular o, lo que es lo mismo, hábito de vida saludable.

Este hábito que debe crearse desde las edades de escolarización, permitirá al sujeto desarrollar un proceso de entrenamiento a lo largo de su vida, con la consiguiente mejora sistemática y progresiva de sus capacidades físicas y/o sociales, incluso en la tercera edad, etapa ésta a la que actualmente se está dedicando más atención, dada la mayor calidad y esperanza de vida, así como del tiempo libre de que dispone esta población, cuyos hábitos de utilización del mismo han variado considerablemente, lo que hará nacer una nueva corriente de EF, a la que denominaremos actividad física para mayores.

Desde la corriente de actividad física y salud habrá que considerar la revisión de aportaciones metodológicas (distribución de cargas, necesidades de recuperación, tipo de actividad, etc...), los criterios de planificación y programación (objetivos, contenidos, temporalización), o los sistemas de evaluación, control y revisión, tanto del proceso como de los resultados.

En el mundo que nos ha tocado vivir, de gran aceleración en el ritmo de vida, las condiciones estresantes en que se desenvuelven muchas personas, demandan actividad física para contrarrestar esas situaciones $y$, por otra parte, los estudios médicos demuestran que la actividad física retrasa la menopausia y, cuando se produce, el ejercicio ayuda a superar la etapa con menores problemas que al tener una vida sedentaria.

El mantenimiento de la actividad física es una necesidad humana para conservar la salud, que es definida por Marcos Becerro (1995), no simplemente, como la ausencia de enfermedad, sino como la sensación de bienestar, la capacidad de ejercer toda clase de funciones, e incluso, la de contribuir a la felicidad propia y a la de los semejantes. Es por este motivo que las administraciones públicas dedican, cada vez más tiempo y presupuesto al fomento de la actividad física como medida preventiva de la salud.

Se desarrolla por medio del modelo que denominamos Mantenimiento o Reactivación, lo mismo que en la corriente siguiente y según a las edades a que vaya dirigido.

\subsection{Corriente de actividad física para mayores}

Los estudios científicos, cada vez más numerosos, relacionados con el tema, aportan datos significativos que refuerzan la hipótesis de que la realización de actividad 
física de forma cotidiana y adaptada a las posibilidades de la persona mejora la salud física y mental mientras que, por el contrario, el sedentarismo favorece y origina enfermedades (Dishman, 1985; American College of Sports Medicine, 1990), citados por Martín Llaudes (1992). La mala adaptación, como consecuencia de la inactividad, reduce las reservas del cuerpo provocando innumerables riesgos para la salud y la capacidad física.

A finales del siglo XXI, la tercera parte de la población mundial tendrá más de sesenta años. En España, los componentes de la llamada tercera edad, han pasado de dos millones y medio en 1960, a seis millones de personas en 1999, lo que supone el $16 \%$ de la población. La familia tradicional, compuesta por muchos jóvenes y pocas personas mayores, está cambiando, dando paso a una nueva, en la que la presencia de mayores es superior.

La tercera edad ha dejado de ser una etapa de llegada, para convertirse en otra vital, cada vez más larga, en la que las personas tienen buena salud y necesidades diferentes. La esperanza de vida ha aumentado considerablemente (74 años para los hombres y 81 para las mujeres) y el estado del bienestar, facilita la continuidad del desarrollo de este colectivo social. Todo ello obliga a pensar en la cuarta edad o última fase de la ancianidad, constituida por aquellas personas que necesitan una ayuda asistencial y/o médica muy específica. Los demás, sin previa planificación, realizan alguna actividad física, bien en los centros sociales a los que asisten, en los que, preferentemente los varones, juegan al billar, ajedrez, dominó y cartas o las mujeres realizan manualizaciones, o simplemente andan, aunque sólo sea para asistir al centro de día de mayores, como se denomina.

A pesar del incremento considerable del número de mayores que ha adoptado hábitos de práctica física diaria y las perspectivas de un aumento proporcional de las cifras demográficas que sitúan a la población mayor como el grupo más numeroso en los próximos años, las instituciones tradicionalmente han dirigido sus programas de actividades a otros núcleos de población y sólo en porcentajes muy bajos, y siempre insuficientes, han ofertado determinados programas especiales orientados a nuestros mayores.

En la actualidad se empieza a tener conciencia de esta nueva necesidad e importante demanda de usuarios, confeccionando y desarrollando actividades, cada vez más variadas, dirigidas de forma específica a este colectivo. Este interés se pone de manifiesto por la aparición de un número considerable de estudios que abordan el tema y aunque la mayoría siguen teniendo un marcado carácter médico cada vez es mayor el número de nuevas perspectivas relacionadas con el campo social, con el educativo y con la actividad física.

La calidad de vida de la persona es el punto de referencia obligado en esta evolución, desde la doble perspectiva de evitar la aparición de enfermedades relacionadas con la ausencia de actividad y prolongar o mejorar, en la medida de lo posible, las prácticas físicas de las personas.

Borms (1995), resaltando este aspecto, apunta la posibilidad de que la mitad del declive de la capacidad física de las personas de edad aparezca como consecuencia de la falta de uso y de la inactividad física, y la otra mitad se deba exclusivamente a la evolución lógica sufrida como consecuencia de la edad. En cualquier caso, considera este autor, que en el primer factor se puede incidir y mejorar al ser reversible. Hay que reseñar, no obstante, que modificar posibles hábitos negativos adquiridos a lo largo de la vida puede suponer una empresa de gran complejidad. 
Sin embargo, son muchas las mejoras, constatadas científicamente, que produce el ejercicio físico. Odriozola (1986), en Jaenes (1992), por ejemplo, apunta que un entrenamiento físico adecuado puede producir una mejora profunda de las funciones esenciales para mantener la buena forma física, en términos fundamentalmente de autonomía e independencia en edades avanzadas, posponiendo el deterioro físico con efectividad entre 10 y 20 años con respeto a personas sedentarias.

Planteamos, por tanto, la necesidad de establecer unas líneas directrices generales o pautas de actuación a considerar en los programas de actividades físicas para los mayores. Entre las más destacadas debemos profundizar en el conocimiento de sus motivaciones, las características fundamentales que los definen, los posibles intereses que les acercan a la práctica, las necesidades reales, etc.

Es evidente que aunque estas actividades no vayan dirigidas a edades escolares, a pesar de ser la salud un núcleo de contenidos del área de EF en todos los niveles de enseñanza, deben ser ciertamente individualizadas, dotadas de la suficiente información, con la comprensión de su utilidad y la garantía de su seguridad y efectividad por parte del ejecutante, para que como consecuencia se obtenga una valoración positiva.

El planteamiento de este trabajo se enfoca, en todo momento, desde la premisa de búsqueda del aumento, o en su caso mantenimiento, de los niveles de salud de nuestros mayores basándonos en la mejora de su capacidad física y, como consecuencia, la posibilidad de incrementar los parámetros de calidad de vida ajustados de forma individual a cada uno.

Las perspectivas futuras parecen indicar que se abre una nueva dimensión en el campo de estudio y desarrollo de la actividad física, el deporte y ciencias afines orientados al grupo de población de mayores, es por ello que veremos a continuación una serie de consideraciones generales sobre la actividad física en dicho colectivo.

Una de las características de estos sujetos es la indefinición de la edad que los delimita, lo que provoca una gran amplitud y, por tanto, extensión del grupo. Otra característica, no menos importante, es el alto grado de heterogeneidad que como consecuencia de lo anterior y de la propia evolución humana refleja este conjunto. No se puede determinar una edad exacta donde localizar el momento de inicio en el que clasificar a una persona dentro del colectivo de mayores o personas de edad avanzada. Sería un error no relacionar este aspecto con su grado de aptitud física, mental y social, de forma interrelacionada y sólo atender aspectos cronológicos. Así, el factor que más se presta a confusión, en las investigaciones científicas al respecto, es la intervariabilidad existente entre los integrantes de este colectivo. La generalización puede conducir a graves errores.

En este sentido encontramos algunos estudios, citados por Jaenes (1992) que, ofrecen cifras significativas y, concluyen que entre los 25 y 30 años de edad es cuando mejor se encuentra la persona físicamente y a partir de esta edad empieza a declinar. Esta involución se manifiesta hasta en un $30 \%$ en sedentarios hasta alcanzar la edad comprendida entre 60 y 70 años, que es considerada como el umbral de mejora del estado general de nuestro organismo. No obstante, con un adecuado entrenamiento, se pueden alcanzar ciertas mejoras significativas en este mismo margen de tiempo (Andersen y cols, 1996). Sin embargo, los ritmos y velocidades que se dan en el proceso de envejecimiento, son diferentes en cada persona (Borms, 1995).

Un programa de actividad física para mayores con una duración entre 8 y 10 semanas supone, como término medio, un incremento del consumo máximo de oxí- 
geno (VO2 máx.) entre un 10 y un $15 \%$. Andersen y cols (1996) desarrollan un programa, con una duración de 6 meses y una frecuencia de dos días a la semana, obteniendo mejoras entre un 4 y un $8 \%$. En él, los mayores incrementos se producen en la fuerza de los músculos anteriores que en mujeres es de un $27 \%$ y en hombres de un $17 \%$, mientras que en los posteriores sólo se incrementa en mujeres un $10 \%$. No obstante, en este amplio espectro de población encontraremos personas que son capaces de realizar marcas o hazañas sorprendentes en pruebas deportivas y otras que, por el contrario, tienen verdaderas dificultades para desenvolverse con normalidad en las más simples actividades cotidianas. Lo que confirma que las diferencias están sujetas a un cúmulo de variables difíciles de cuantificar (estilo de vida, alimentación, estatus social, trabajo desarrollado, etc.).

Aunque los datos no han sido del todo probados, desde una perspectiva experimental, Pollock y col. (1978), en Jaenes (1992) sugieren que en personas de mayor edad es necesario un $40 \%$ más de tiempo para la adaptación al entrenamiento por cada década de vida por encima de los 30 años. Así, mientras que personas de 30 años hacen algún progreso cada semana, las de 50 años lo hacen cada dos semanas, y las de 70 años cada 3 o 4 semanas.

Como consecuencia de esta nueva tendencia de la EF surge un nuevo modelo de enseñanza al que hemos denominado de Mantenimiento o Reactivación, como se ha citado en la corriente anterior.

\subsection{Corriente de Actividad Física y Turismo}

Como consecuencia de los cambios socioeconómicos que se han producido en nuestro país, ha aparecido, creemos que con bastante futuro, el turismo de la tercera edad, juvenil, científico o de congresos, el fomentado por colectivos concretos relacionados con la cultura, el arte, las profesiones, etc... Es aquí donde la Naturaleza está, y puede seguir jugando, un papel preponderante en el desarrollo turístico y es ahí, en el impacto social que presenta esta nueva concepción del turismo relacionado con la actividad física, donde nos basamos para sostener su importancia como nueva tendencia de la EF.

Porque en la cultura de culto al cuerpo, éste y el turismo, se alían para ocupar el ocio en lo que se conoce como terapia vacacional, como una nueva forma de hacer turismo, en la que se conjugan cursos sobre nuevas técnicas corporales, bioenergéticas o comunicativas, y donde, el conocimiento del folclore y las fórmulas artesanales, también tienen cabida, dando lugar a un turismo más activo y más sano, alejado de la contaminación de las grandes ciudades.

Así lo hace constar el Programa de las Naciones Unidas para el Medio Ambiente, en colaboración con la Organización Mundial del Turismo, donde expresa la convicción de que el desarrollo armónico de las actividades de vacaciones y tiempo libre y una buena gestión del medio ambiente y patrimonio cultural llevan a perfeccionar la calidad de vida de las personas.

Es evidente que el deporte forma parte de la cultura, que para el conocimiento de algunos aspectos de ésta (arquitectónicos, pictóricos, ecológicos, urbanísticos, bibliográficos, gastronómicos, etc...), nos desplazamos a otros lugares utilizando diferentes medios de transporte (autobús, tren, coche, moto, bicicleta, a pie...) y que a eso le llamamos "hacer turismo". Pues bien, si somos capaces de sistematizar esa actividad, diseñando una programación que nos permita realizar ejercicio físico (circuitos urba- 
nos, recorridos naturales, senderismo, asistencia a eventos deportivos...) mientras accedemos a cualquiera de los aspectos culturales que se han señalado, podremos armonizar el turismo con la actividad física.

A estas actividades podríamos sumar otras que, cercanas a los deportes de aventura señalados, planteadas con diferentes objetivos, ocuparían parte de los contenidos de la corriente que estamos exponiendo. Estas actividades pueden ser la natación y otros deportes acuáticos, el esquí y otros deportes en la nieve, así como aquellos deportes de innovación cuya realización está prevista en las playas (voley-playa; bádminton, fútbol playa, etc...), o en el aire (paracaidismo, ala delta, parapente...).

Así, la aplicación de esta corriente en los centros escolares, permite la elaboración de actividades conjuntas con otras áreas que configuran el currículum escolar y, como consecuencia surge el modelo educativo que por sus características de interdisciplinariedad con otras materias e innovación en el currículo escolar, desde su acercamiento a otros aspectos educativos a través de la motricidad, hemos denominado Cultural. Las habilidades básicas y los aspectos cognitivos y sociomotrices, son los más importantes a desarrollar en su ámbito de aplicación motriz.

Muy cercano a otras corrientes culturales en alza en la sociedad actual, tales como el turismo rural o actividades físicas en el medio natural (senderismo, acampadas, etc...), a través de este modelo se pretende acercar a los estudiantes a los núcleos más alejados de sus centros de población y conocer otros sistemas de vida, rurales o urbanos, y distintos enfoques de la actividad física en la naturaleza, recreación o cultura, inaccesibles sin estos planteamientos.

Con el milenio que hemos comenzado, la humanidad se enfrenta, en los próximos años, a un desafío científico y tecnológico sin precedentes. Entre sus claves, ciencia y tecnología; vida cotidiana; geopolítica; medicina y salud; se encuentran también el ocio y la cultura. El largo plazo no se prepara previéndolo, sino optando por la diversidad (Punset, 1999,42), en ella, será posible plantear la relación entre el turismo y la actividad física, además de los distintos contenidos que contempla la EF. El capital cultural y medio ambiental, constituyen un inmenso patrimonio para la generación de riqueza, los medios para acceder a ella pueden ser el turismo y la actividad física.

El turismo, como fenómeno de masas, surge después de la segunda guerra mundial, como consecuencia del crecimiento económico y mayor poder adquisitivo de la población, sobre todo de los países industrializados, que permitían a los usuarios de esta actividad, disponer de más tiempo libre, para dedicarlo al disfrute del ocio.

La promoción del turismo se considera una herramienta importante en la política económica de los países menos desarrollados, que cuenta con el apoyo de los organismos internacionales como la ONU, la Organización Mundial del Turismo, el Banco Mundial, etc... Sin embargo, el problema aparece cuando el país receptor considera esta actividad, sólo como una fuente ingresos, porque, muy al contrario, el turismo necesita a su alrededor, una amplia infraestructura de inversiones considerables que, a largo o medio plazo, reportarán mayores y más estables beneficios económicos y sociales, y es aquí donde los especialistas en EF deben plantearse también este tipo de intervención.

Si consideramos que el ocio es el disfrute de la mayor parte del tiempo libre del que dispone la sociedad actual, la cual admite y reconoce que a la conservación de la salud se accede practicando ejercicio físico y que, al mismo tiempo, la cultura de elites, mediante los medios de comunicación, ha pasado a ser cultura de masas. Si las aspiraciones económicas de muchos países, se ven satisfechas por el sector de servicios 
que se mueve alrededor de los fenómenos cultural, deportivo y turístico. Y si, además el turismo es una actividad recreativa y cultural a la que se puede acceder de diferentes formas, entre ellas practicando actividad física (distintos tipos de senderismos, distintos tipos de marchas, deportes de nieve, deportes de montaña, deportes acuáticos, etc...), lógicamente, el turismo y la actividad física confluyen en una unidad.

Con esta descripción tratamos de evidenciar que existe una corriente de $\mathrm{EF}$, que se practica actualmente de alguna manera, pero cuyos aspectos teóricos demandan una adecuada fundamentación que permita avanzar alrededor de diferentes currícula en los ámbitos que abarca la actividad física, es decir, senderismo en sus vertientes de a pie, a caballo, en bicicleta o en $4 \times 4$, distintos tipos de semanas (blanca, azul y verde), acampadas, marchas, deportes de aventura y/o riesgo, actividades recreativas, deportes adaptados, deportes de alto nivel económico, ecoturismo, bioturismo, turismo cultural y todas aquellas actividades que se realizan en función del turismo, pero que requieren para su puesta en práctica diferentes formas de actividad física.

Por tanto, esta incipiente corriente, puede llegar a configurarse como una de las más importantes, por los aspectos que contempla y la población a quien alcanza, destacando dentro de las nuevas tendencias del turismo:

1. Turismo Verde o Ecológico y sus distintas modalidades, que trata de acercar al hombre a la naturaleza, permitiéndole, en condiciones de razonable seguridad, realizar algún tipo de aventura sin que esto suponga un deterioro para el equilibrio ecológico del medio ambiente. Debe contar con un buen asesoramiento técnico y tener una buena forma física, para evitar accidentes. Dentro de sus modalidades están:

- Excursiones por caminos forestales y senderos.

- Rutas para vehículos todo terreno.

- Turismo ecuestre de montaña.

- Turismo aéreo (con motor (ultraligeros, paramotor...), o sin motor (parapente, ala delta, planeadores, globo...).

- Turismo fluvial (piragüismo, windsuf...).

- Cicloturismo.

- Caza fotográfica.

- Montañismo, Escalada y Espeleología.

2. Turismo Rural, término inconcreto, que se confunde con el de espacio rural o sociedad rural, no existiendo ninguna definición consensuada, ni siquiera en la Unión Europea, no obstante, creemos conveniente alejarnos del concepto tradicional donde sólo se barajaba la posibilidad de alojamiento y manutención en zonas rurales, a lo que hay que añadir otros aspectos a los que nos venimos refiriendo, como son el patrimonio histórico-cultural, el conocimiento de otras gentes y sus formas de vida, la vida en la naturaleza y las actividades deportivas que se pueden realizar en ella. Todo ello lo podemos concretar en las siguientes tipologías y productos que lo componen:

- Alojamiento (camping, hoteles, casas de campo, casas rurales, etc...).

- Actividades deportivas (excursiones, rutas a caballo, a pie, en bicicleta, en 4x4, parapente, ala delta, descenso de barrancos, náutica, etc...).

- Restauración (gastronomía, productos naturales, etc...). 
Dando lugar a los distintos tipos de turismo, directamente relacionados con la actividad física, que citamos a continuación:

- Ecoturismo o turismo de naturaleza que contribuye realmente a la conservación medio ambiental.

- Turismo Verde.

- Turismo de Interior.

- Turismo Cultural.

- Turismo de Aventura.

- Turismo Deportivo.

- Agroturismo (se caracteriza por utilizar como alojamiento las propias casas rurales, cortijos, casas de campo, etc...).

3. Deportes en la Naturaleza, en los que se incluyen las actividades físico-deportivo-recreativas en la Naturaleza, en función del medio físico en que se lleven a la práctica, para lo que podemos prever, un calendario de actuación que puede establecerse por "semanas", que se denominan de diferente forma, según el tipo de actividad a desarrollar. La más practicada como tal, es la "semana blanca", a realizar en estaciones de esquí. Por otra parte, empieza a difundirse la "semana verde", que será la que se disfrute en la naturaleza, en parques naturales, campamentos, aulas en la naturaleza, refugios de montaña..., y por último, la "semana azul", que ubicaremos en playas, ríos, pantanos y piscinas, más fácil de celebrar en aquellas poblaciones costeras, más peligrosa por tratarse de un elemento adverso, más cara, por el precio del material necesario, pero muy interesante a la hora de realizar deportes y actividades físicas de moda, con la posibilidad de incluir, también, deportes alternativos (voley playa, fútbol playa...), cuya realización en playas o zonas arenosas permite mayor recreación y menor competitividad.

Los deportes de riesgo, como puenting, descensos de ríos, alpinismo, espeleología, que demandan una gran preparación física y psíquica, además de aprendizajes teóricos muy importantes, se escapan al pensamiento de recreación y ocio enfocados hacia la cultura del resto de los deportes que ocupan este espacio, no obstante se incluyen en la clasificación más elemental de actividades físico-deportivas recreativas, en función del elemento implicado o medio en que se desarrollen

Creemos que la interrelación de deporte y turismo, que gira en función de la actividad física y la cultura, empieza a despuntar como fenómeno de elites (juventud, economías más fuertes, climatologías adecuadas...) y, poco a poco, se va abriendo paso hacia su generalización y aceptación como cultura de masas. En este sentido, el modelo Cultural, viene a integrar la corriente de actividad física y salud, con la de actividad física y turismo. El turismo tiene el doble objeto de ejercicio y recreo, este último, basado en el anterior, es de gran importancia para obtener resultados positivos en educación, que pueden trasladarse a diferentes etapas de la vida y repercutirán directamente en resultados culturales.

\subsection{Corriente de Culto al cuerpo}

De manera paralela a las tres corrientes que acabamos de exponer (actividad física-salud; actividad física para mayores y actividad física y turismo), podemos considerar la existencia de una nueva tendencia o corriente de la EF, a la que vamos a 
denominar de "Culto al cuerpo", que se instaura entre la población de cualquier edad a la búsqueda del cuerpo ideal que hace propio la sociedad en que vivimos.

Esta corriente surge de la comprensión del concepto de cuerpo en nuestra sociedad, entendiendo por ésta, la española de finales del siglo XX, la de la España democrática, que no difiere demasiado del resto de sociedades occidentales democráticas de Europa.

Por eso en este apartado vamos a exponer las diferentes formas de entender el cuerpo que se traslucen de las diversas prácticas y usos sociales del mismo. La alta valoración del cuerpo y de lo corporal en nuestra sociedad resulta una cuestión controvertida desde varios puntos de vista. La respuesta a una hipotética encuesta en la que se cuestionara sobre la existencia o no del "culto al cuerpo" en cualquier capa social, sería probablemente afirmativa.

Aunque algunas voces pretenden presentar el fenómeno de la valoración social del cuerpo como algo surgido en nuestro tiempo, una muestra de que esto no es así puede estar en la descripción del cuerpo y de las actitudes que deberían poseer los ciudadanos del "medievo cristiano" que quisieran ser considerados "nobles" y no "viles", las cuales aparecen en los manuales de caballería que recoge Vicente Pedraz. Podríamos recurrir igualmente al ideal corporal griego, o al tratamiento de esta cuestión en otras culturas y en otros tiempos, pero ello rebasaría nuestros objetivos.

Con respecto a la mujer, más implicada, al menos teóricamente en los conceptos de esta corriente, durante muchos años se ha considerado deseable a una mujer de cuerpo relleno. La moda era estar gorda. La explicación a este modelo procede de la creencia cultural de que estar gorda significaba ser atractiva y estar sana, en una sociedad donde escaseaban los alimentos y las enfermedades endémicas eliminaban a gran número de personas. Un cuerpo femenino lleno de curvas indicaba que el cabeza de familia era una persona acaudalada y que la mujer tenía reservas para proteger a su familia en épocas de escasez.

En los últimos setenta y cinco años, las cosas han cambiado al haber una provisión de comida y buena distribución de alimentos en el mundo occidental, originando una modificación en el pensamiento, mediante la cual el estar delgada se convierte en una moda. Concursos de belleza con mujeres escuálidas, proliferación de libros con regímenes alimenticios, productos adelgazantes anunciados en los medios de comunicación y vendidos en herbolarios y farmacias, han llevado a la sociedad a pensar en el tipo de mujer atractiva como delgada.

Además, la publicidad, induce a unos hábitos alimenticios, vendidos como saludables y con pretensiones científicas, que son aceptados sin otra garantía que el hecho de ser expuestos en televisión, se trata de los productos etiquetados como "light, bio, naturales, integrales, sanos, bajos en calorías, libres de grasas, oligoelementos, bífidos activos o biorreguladores", cuyo consumo, no conseguirá, en absoluto, que al mirarse en el espejo se refleje la imagen de las consabidas modelos.

Desde otra óptica, hay quien ve en la valoración del cuerpo en la sociedad actual una cuestión ambigua, es decir, por un lado observa claros indicios que potencian y ensalzan el valor de lo corporal en el seno de la sociedad, y por otro, detecta una "cultura contra el cuerpo" (la explotación laboral y competitiva del cuerpo, su ignorancia en las etapas escolares, etc.), tal es el caso de Vázquez (1989).

La EF, de manera tradicional, ha defendido un modelo de practicante de ejercicio físico, cercano a la consabida expresión acuñada por los griegos, mente sana en cuerpo 
sano, y lejos de los cánones actuales en los que se recomienda para todos por sus características de desarrollo de la motricidad, mejora de la salud y condición física, recreación y socialización, entre otras. La EF escolar encierra un carácter preventivo, que hemos de tratar de evidenciar en nuestras actuaciones para no caer en lo que dice el proverbio turco: "Cuando el carro se ha roto muchos os dirán por donde no se debía pasar".

Para apoyar estos planteamientos, veremos a continuación algunos enfoques sociológicos a propósito del cuerpo.

Si distinguimos entre "social" y "sociológico", lo social es aquello que surge de la sociedad o está en ella, todo hecho o acción que se desarrolla colectivamente en el seno de la sociedad; lo sociológico sería lo que se deriva del estudio o análisis de tales fenómenos sociales, realizado desde la Sociología. Pues bien, desde un enfoque sociológico, las cotas alcanzadas por la valoración y la dedicación al cuerpo en la sociedad occidental podrían deberse a varios hechos que la caracterizan, algunos de los cuales ya se han citado, y que en conjunto son:

- El desplazamiento de la población de las zonas rurales a las ciudades lleva consigo un tipo de vida sedentaria en espacios reducidos. La válvula de escape más generalizada es la búsqueda de movimiento y de espacios.

- Debido a la organización de la jornada laboral, se tiene más tiempo libre para el empleo del ocio.

- El aumento del nivel de vida depara mayores posibilidades económicas para dedicarlas a las ofertas publicitarias relativas al cuerpo y su cuidado, tanto de varones como de mujeres.

- Ha aumentado considerablemente la esperanza de vida y el estado de salud en la tercera edad.

- El descenso del índice de natalidad, y la incorporación de la mujer al mercado laboral, permiten a ésta mayores posibilidades de atención a su cuerpo.

Parafraseando a Bourdieu, Shilling (1993, 97-98), desde la teoría social, centra la cuestión en nuestro campo de estudio y habla de "capital físico" para denominar a los referidos modelos y usos corporales hegemónicos impuestos al resto de grupos sociales; por ejemplo el modelo de salud (apariencia corporal mesomórfica y juvenil, actitud moral de no fumar, no drogarse o no consumir alcohol).

La delgadez se ha convertido para algunas mujeres, cada vez más jóvenes, y también para algunos hombres, en una especie de culto del que no pueden prescindir. Sacrifican horas enteras dedicadas al ejercicio físico para conseguir adelgazar, algunos llegan a caer en enfermedades por dependencia, como es el caso de la anorexia y la bulimia, y otros, realizan ejercicio físico para mantenerse en forma, por placer e incluso para conseguir y conservar un cuerpo esbelto, los primeros engrosarían las listas de la actividad física para alumnos con necesidades educativas especiales, los segundos, son los que originan la corriente de la EF que estamos tratando, abriendo posibilidades laborales de actuación en otros campos que no son el educativo o el municipal. De ella se ocuparía el modelo que hemos denominado de Mantenimiento.

\subsection{La EF en la Transversalidad}

No podemos terminar esta exposición sin hacer una breve alusión a la transversalidad por la importancia que presenta en el currículum escolar, a pesar del poco interés que despierta entre los profesionales de la enseñanza, en general. 
El Ministerio de Educación y Ciencia, en su día, hoy Ministerio de Educación, Cultura y Deporte (MECD), propone como temas transversales la Educación Ambiental; la Educación para la Paz; la Educación Moral y Cívica; la Educación para la Igualdad; la Educación para la Salud; la Educación Vial; la Educación en la Sexualidad; y la Educación para el Consumidor, a los que las Comunidades Autónomas con competencias en Educación, realizan alguna modificación al diseño original, así, la Consejería de Educación y Ciencia de la Junta de Andalucía (CECJA), por ejemplo, propone los siguientes: Educación para la salud. Educación Ambiental. Las Nuevas Tecnologías. Educación para la Paz. Coeducación. Educación del consumidor y usuario. Educación vial.

Es evidente que los temas transversales enumerados, recogen las características señaladas como componentes de la socialización del cuerpo, pero además, los seres humanos tienen otras preocupaciones relacionadas con el mundo en el que viven, que consideramos de gran importancia en la transversalidad educativa, especialmente la educación para la solidaridad, en relación directa con los movimientos migratorios que se están produciendo en la actualidad o las diferencias socio-económicas del mundo occidental con el resto de países, donde podemos incluir también la educación para el desarrollo, la educación para la calidad de vida, muy relacionada con la educación para la salud, la educación ética y moral, la educación intercultural desde la base de la cultura propia de la comunidad en que se lleve a la práctica el diseño curricular y la igualdad de oportunidades, donde siguiendo el modelo de la CECJA, trataremos de relacionar en un único punto el tratamiento de la educación de la sexualidad y para la igualdad de oportunidades entre hombres y mujeres desde la perspectiva de la coeducación.

El Sistema Educativo Español, a través de la LOGSE, hace suyas estas preocupaciones sociales, dándole el tratamiento didáctico que requieren a través de los temas transversales, definidos en el DCB, como "contenidos educativos valiosos que responden a un proyecto válido de sociedad y de educación y que, por consiguiente, están plenamente justificados dentro del marco social en el que ha de desarrollarse toda la educación".

El concepto de transversalidad en educación se desarrolla en las sociedades más avanzadas, en el intento de humanizar el proceso de enseñanza-aprendizaje, en una sociedad cambiante y agresiva, donde los valores han de ser mantenidos y/o recuperados. La relevancia social de los temas transversales, aconseja su estudio de manera independiente $y$, en nuestro caso, en relación con la EF porque, según la normativa oficial estos temas estarán presentes a través de las diferentes y correspondientes áreas a lo largo de la etapa educativa.

Si la educación tiene como finalidad básica el desarrollo integral y armónico de los alumnos y alumnas, dentro de un contexto social real, es necesario que se incluya en el currículum escolar, a través de los proyectos de centro y curriculares, todo aquello relacionado con la educación en valores, que es en definitiva lo que pretendemos conseguir con los temas transversales.

Las principales características que presentan estos temas son la actualidad, la referencia explícita a valores y actitudes y la importancia de su desarrollo dentro de las diferentes áreas curriculares. Para Yus $(1996,11)$, "los temas transversales son un conjunto de contenidos educativos y ejes conductores de la actividad escolar que, no estando ligados a ninguna materia en particular, se puede considerar que son comu- 
nes a todas, de forma que, más que crear disciplinas nuevas, se ve conveniente que su tratamiento sea transversal en el currículum global del centro".

Por su parte, Celorio $(1996,32)$ considera que están en contra de los modelos educativos insolidarios; que no deben ser estudiados como materia curricular, sino con un enfoque crítico, orientador y dinámico; que deben renovar los sistemas de enseñanza-aprendizaje; que deben conocerse los intereses y problemas del alumnado para partir y educar desde ellos; que intentan abordar visiones interdisciplinares, globales y complejas, más fáciles de entender desde otra óptica que la estrictamente curricular; que necesitan desarrollarse en un ambiente de cooperación y participación en el aula, porque para construir conocimiento que facilite la vida futura del alumnado hay que conectar primero con sus intereses.

En el área que nos ocupa, la relación de los temas transversales con la EF, la encontramos en primer lugar al tratar la Educación para la salud.

El modelo dominante de salud en la actualidad podría sintetizarse como el que pretende el alejamiento de hábitos nocivos como el sedentarismo, el consumo de drogas, tabaco, alcohol, etc... y el acercamiento a los hábitos saludables como la práctica de cualquiera de las ofertas hegemónicas de actividad física: deporte, trabajo en los gimnasios, uso de aparatos anunciados por televisión, actividades de aventura, etc... En cualquier caso, este modelo está normalmente ligado a la noción de cuerpo ideal, que ya hemos descrito como, juvenil, mesomórfico, sexualizado... (Deward, 1993).

La civilización del ocio, como quiera que sustituye a la del trabajo y se produce por el mayor tiempo libre de que disponen las personas, las mejores condiciones socio-económicas y el aumento de la esperanza de vida, permitirá en el futuro dedicarse a otras actividades que influenciadas por el beneficio que para la salud reporta la actividad física, se realizarán alrededor de ella. A partir de esta premisa, intentaremos ofrecer a nuestros alumnos la relación que existe entre la salud con la actividad física, ya tratada en la corriente correspondiente. El concepto de salud en la actualidad conlleva aspectos físicos y psíquicos. Es por tanto evidente su relación con la actividad física.

En relación a la Educación Ambiental, desde el área de EF, puede plantearse a través de las actividades en la Naturaleza, para conocer el contexto que nos rodea, urbano o natural, y los beneficios o riesgos que conlleva su cuidado y protección para no llegar a la degeneración medio ambiental.

Las Nuevas Tecnologías por su parte, aunque no están recogidas expresamente en la normativa del MEC, deben ser incluidas como eje transversal, dada la inusitada incidencia que están adquiriendo entre los todos ciudadanos.

Una de las formas de introducir las nuevas tecnologías en los Centros, en consonancia con la transversalidad que proponemos, puede ser a través del área de EF, como apoyo en el aula tradicional a las actividades del gimnasio. En este sentido, creemos que el visionado de vídeos con películas educativas alrededor del deporte o sobre deportes específicos, bien para ver los comportamientos sociomotrices que se producen, bien para la observación de técnicas y tácticas acordes con las edades de los alumnos a los que vayan dirigidos, así como para observar sus propios comportamientos tras un partido de cualquier deporte o de la clase, puede ser un material de extraordinaria validez apoyado en las nuevas tecnologías, que les ayudará a reflexionar sobre su propia práctica y a realizar críticas constructivas al respecto. 
La informática al servicio de la actividad física escolar, es otro ámbito importante de las nuevas tecnologías aplicadas a nuestro currículum, así, los CD-Rom de juegos, constituyen, al principio de su uso, una forma de desarrollar las habilidades motrices finas, más tarde pueden llegar a convertirse en peligrosos, por la adicción que conllevan y el tiempo que requieren delante de la consola o del ordenador, en detrimento de la actividad física y las relaciones sociales que podrían establecer en sus ratos de ocio. Por otra parte, internet, es una fuente inagotable de información en lo que a educación, actividad física y deporte se refiere, por tal motivo, el alumnado, en cuyos centros exista aula de informática con conexión a la red, pueden realizar como ejercicios la búsqueda de documentación sobre los temas de nuestra materia.

La prensa y TV, son otros recursos de las nuevas tecnologías, susceptibles de ser utilizados por el profesor o profesora de EF en particular y de educación, en general, en transversalidad con el campo de la actividad física, mediante análisis de fotos o eventos deportivos que pudieran aparecer en dichos medios.

Sobre la Educación para la Paz, es evidente que la paz es la ausencia de la guerra, pero la paz a la que nos queremos referir es algo más cotidiano, es aquella que debe establecerse desde la primera infancia en el seno familiar y en el centro educativo al que acceden nuestros escolares desde que pisan por primera vez un parvulario, es la que debemos transmitirles desde el currículum oculto, es algo tangible que sentará las bases de unas buenas relaciones humanas y de una futura convivencia pacífica entre ciudadanos y ciudadanas de su entorno más cercano, de comunidades más lejanas y del mundo.

Con el deporte, como hemos visto en la corriente multideportiva, aprenderán a respetar al contrario, a colaborar con sus compañeros, a respetar las reglas del juego y las normas de los entrenamientos, haciendo bueno el eslogan que acuñará en Gran Bretaña Thomas Arnold, "fair play o juego limpio". En este punto, la tarea del profesorado de EF es importantísima, ya que, lejos de reproducir los lamentables comportamientos de algunos entrenadores de equipos de elite y de otras categorías inferiores y hasta infantiles, deben basar su actuación en conseguir que la participación deportiva sea divertida, gratificante, recreativa, socializante y sobre todo participativa. La adquisición de estas conductas alrededor de la actividad física hará posible una sociedad que luche por vivir en paz.

Incluimos también en esta corriente la Coeducación, considerando que el marco legal donde se apoya la igualdad de oportunidades, comienza en la Constitución Española de 1978, en sus artículos, 9.2 y 14, donde se prohibe expresamente cualquier tipo de discriminación por razón de sexo y se establece la obligación que corresponde a los poderes públicos de promover las condiciones para que la igualdad de las personas sea efectiva y real.

La LOGSE, acentúa el principio de no discriminación por razón de sexo en su Preámbulo y posterior articulado, estableciendo, como uno de los objetivos generales de la educación, proporcionar a niños y niñas, a los jóvenes de uno u otro sexo, la formación plena que les permita conformar su propia y esencial realidad, que integre a la vez, el conocimiento y valoración ética y moral de la misma.

Con el establecimiento de este objetivo, el camino hacia una escuela coeducativa que contribuya a formar personas autónomas y críticas, capaces de relacionarse positivamente con los demás, más allá del hecho biológico de ser hombre o mujer, está 
iniciado. Pero la diferencia entre la teoría y la práctica, sigue siendo un hecho constatable que, a través del eje transversal que estamos desarrollando, debe mitigarse.

Los valores culturales que tradicionalmente ha ido transmitiendo la escuela, han encerrado actitudes diferenciales, según fueran dirigidos a niñas o niños, en base a una sociedad patriarcal y a modo de currículum oculto, desarrollando comportamientos y roles distintos demandados por esa sociedad donde se lleva a la práctica el currículo, por estos motivos, habrá que diseñar un proyecto de centro que incluya otro de cambio en las actuaciones de equipos directivos, profesorado, padres y madres y alumnos y alumnas.

La coeducación, por tanto, resulta de promover la igualdad real de trato entre ambos sexos, supone no aceptar como universal el modelo masculino, corregir los estereotipos sexistas tradicionalmente establecidos, desarrollar individualmente las cualidades de cada individuo, independientemente de su sexo y proponer un currículo equilibrado que elimine los sesgos sexistas existentes en la sociedad. Incluye la educación afectiva, sexual y de igualdad de oportunidades, bloque que en otras comunidades autónomas, figura como eje transversal independiente.

Con respecto a la $\mathrm{EF}$, los grandes avances que se han producido en nuestra sociedad a lo largo de todo el siglo XX, a partir de las reivindicaciones de la mujer y el desarrollo de un marco legal igualitario, han permitido pasar, desde la Ley Moyano (1857), en la que no se contemplaba este tipo de educación para las mujeres y, para los varones, a partir de los diez años se realizaba un tipo de gimnasia premilitar, a una EF con los mismos objetivos, contenidos, metodología y evaluación, recogida en la LOGSE, indiferenciadamente para ambos sexos, todo ello considerando el carácter de individualización en la enseñanza.

Durante el primer tercio del siglo XX, la EF femenina, con contenidos diferentes a la masculina, desarrolla, sobre todo, la danza y las gimnasias rítmica y sueca, mientras que la masculina, adopta el modelo deportivo y premilitar. Esto sigue ocurriendo, en teoría, hasta la Ley de Educación de 1970, que establece la enseñanza mixta en todos los centros públicos del País, sin embargo, en la práctica se mantiene de manera parecida, hasta bien entrada la década de los ochenta (en 1985, sólo el 23\% de las mujeres declaran practicar bastante o algún tipo de deporte, frente al $46 \%$ de los varones) y de forma definitiva, tras la implantación de la LOGSE, a lo largo de la década de los noventa.

Otro eje transversal que relacionamos con la EF en esta corriente es la Educación del consumidor y usuario, ya que en la sociedad de la opulencia en que vivimos, la educación de niños y niñas, en función del posible consumismo a que se verán abocados, ha de pasar por el conocimiento del buen uso de los bienes materiales que se les ofertan desde cualquier ámbito, muy especialmente desde los medios de comunicación.

La educación del consumidor, que llegó a los centros educativos a finales de la década de los setenta, apoyada algunos años más tarde por las administraciones públicas, surge porque está constatado que el consumo es un hecho social sin edad, y son los niños y niñas los receptores habituales de mensajes publicitarios emitidos por la TV, fundamentalmente, que inducen al consumismo y ejercen gran influencia en la familia.

En el caso de la EF, en edades más tempranas las marcas deportivas de vestuario y zapatillas de deporte, son los elementos más demandados por los escolares, pudien- 
do el profesorado de la materia establecer conceptos de utilidad, que no han de pasar por el consumo de determinadas marcas y sí de higiene y aseo personal. Por su parte, sobre los juguetes, introducidos en la pequeña pantalla hasta la saciedad, el profesorado está también capacitado para influir sobre sus alumnos y alumnas, explicando cuales son aquellos que usarán y que les van a permitir realizar actividad física y relacionarse al mismo tiempo con sus amistades y/o con el medio natural.

Respecto a la alimentación y los hábitos alimentarios que se desarrollarán a partir de las edades escolares, la publicidad, en ocasiones, demasiado engañosa y fácil en el uso doméstico, demanda de los niños y niñas el consumo excesivo de determinados productos, siendo también muy importante el consejo que el profesor o profesora de EF puede ofrecer sobre los principios básicos de la nutrición y el beneficio de una buena alimentación en edades de crecimiento.

En edades superiores, concretamente en la pubertad y adolescencia, el culto al cuerpo que ha invadido nuestra cultura occidental, demanda de nuestros jóvenes dietas alimenticias desequilibradas y excesivo ejercicio físico para conseguir una buena figura. El peligro que entrañan estas actitudes, en el intento de imitar el consabido modelo publicitario, puede pasar por el consumo de determinadas drogas, especialmente por parte de los varones, al efecto de conseguir mayor masa muscular y, en el caso de las chicas, caer en trastornos alimentarios tales como la anorexia y/o bulimia nerviosas.

Por tanto, a través de este eje transversal hemos de concienciar al alumnado de sus responsabilidades como consumidor, evitando conductas consumistas poco deseables, valorando el dinero, lejos del derroche, como un bien que nos permite calidad de vida, al mismo tiempo que deben intentar comprender las desigualdades en la distribución mundial de la riqueza, incidiendo en el desarrollo de conductas de solidaridad y en la valoración de las personas por sus virtudes y no por su poder adquisitivo, en nuestro caso, muy especialmente alrededor de las marcas y productos ya citados. En contrapartida, deben conocer además, sus derechos como consumidores, no sólo de productos, sino de instalaciones y material deportivo, ya sea público o privado.

Respecto a la Educación vial, para la CECJA (1992), el concepto de educación vial parte del conocimiento de normas y señales que regulan la circulación de vehículos y personas, por las calzadas y aceras, así como la adquisición de valores, hábitos y actitudes que permiten a los ciudadanos dar una respuesta segura en las distintas situaciones de tráfico en las que se vean inmersos, ya sea como peatón, pasajero o conductor.

Como ámbito de mayor cobertura que engloba la educación vial, podemos considerar también la educación para la vida en sociedad, puesto que la primera, mejorará la calidad de vida de los ciudadanos, que han convertido el coche en un medio indispensable de trabajo y/o desplazamiento que les permite realizar acciones impensables a principios del siglo XX.

Por estos motivos, los alumnos y alumnas han de conocer las reglas y normas de circulación y, para ello, nada prestará mejor ayuda que los circuitos que podamos montar en el centro o sus alrededores, en bicicleta o patines, insistiendo en la prevención de accidentes y pretendiendo alcanzar los siguientes objetivos: Identificar las zonas más seguras para los peatones. Leer correctamente los semáforos. Distinguir entre aceras, calles, calzadas, vehículos y peatones. Comportarse adecuadamente como peatón y como pasajero de un vehículo. Desplazarse por la ciudad con medidas de seguridad personal. 
Además de todos los ejes transversales tratados hasta aquí, podemos considerar la existencia de Otros temas transversales, de gran importancia, que no configuran de manera oficialmente establecida la transversalidad del currículum escolar.

Dedicaremos un breve apartado a aquellas cuestiones que ocupan un papel destacado dentro de la formación integral del alumnado y son susceptibles de desarrollarse, de manera específica o global, a lo largo del período de escolarización. A tal fin, hemos seleccionado los que consideramos de mayor interés en la sociedad actual y local en que vivimos y trataremos de dar una visión de conjunto de ellos.

En primer lugar, y en nuestro caso particular, hemos de referirnos, en este espacio a modo de ejemplo, a la Cultura Andaluza, entendiendo por ella, la que recoge las características socio-económicas, geográficas, políticas, folclóricas, gastronómicas, ecológicas, ambientales, culturales, lingüísticas, históricas, etc... que constituyen la tradición histórica del pueblo andaluz y dan origen a su identidad particular. Como es lógico, el estudio y conocimiento de esta cultura, no debe deslindarse del resto de las que configuran el mapa nacional, europeo y mundial, por esta razón, la educación intercultural desde la base de la cultura propia de la comunidad en que se lleve a la práctica el diseño curricular, ha de verse reflejada en todo momento.

Pero en relación a la EF, nos preguntamos cual es punto que la conexiona con la cultura andaluza y pensamos que puede establecerse desde muchos ámbitos, de ese modo, para acceder al conocimiento de la mayoría de las características descritas, las actividades en la naturaleza y la afinidad entre éstas y el turismo rural, especialmente con los aspectos culturales que recoge, pueden ser un buen incentivo, acción que podríamos realizar también alrededor de eventos deportivos celebrados en la propia comunidad autónoma, así como, el conocimiento de juegos autóctonos, bailes populares, comidas tradicionales similares a la dieta mediterránea, reconocida a nivel médico-científico como base de una buena salud, etc...

Por otra parte, en relación directa con los movimientos migratorios que se están produciendo en la actualidad o las diferencias socio-económicas del mundo occidental con el resto de países, o del norte con el sur, hemos de acometer el estudio y propuestas de acción sobre la educación para la solidaridad, en cierta medida, coincidente con la educación para vivir en sociedad. Para ello, partiremos del aula y del centro escolar, como núcleos sociales en los que se establecen ciertas normas de convivencia y cooperación que permitirán afrontar en cada momento los problemas que se vayan presentando y trasladar en un futuro las soluciones encontradas al mundo en que vivirán.

Creemos que la $\mathrm{EF}$, ofrece grandes posibilidades de intervención, puesto que a través del deporte escolar, los alumnos y alumnas, deben asumir diferentes papeles y posiciones en el juego, permitiendo la participación de todos, sin excepción, a pesar de sus características físicas o afectivas. Deben aprender a ganar y a perder sin traumas que aboquen a comportamientos violentos, físicos o verbales no deseados y a compartir la derrota o la victoria con el resto de sus compañeros de centro, esto equivale a establecer relaciones afectivas satisfactorias que le permiten expresar libremente sentimientos y opiniones propios, desarrollando actitudes de colaboración y consenso.

Aprenderán, entre otras cosas, mediante este tema transversal, a valorar y cuidar su propio cuerpo y a conocerse a sí mismos para, desde ese momento, apreciar y aceptar a los demás, lo cual redundará en la construcción de la realidad social, tanto del grupo como de la comunidad. 
Además, muy relacionada con la educación para la salud, está, la educación para la calidad de vida y, en consecuencia, la educación para el desarrollo, ambas, conectadas a su vez, con la educación del usuario y el consumidor. En este sentido, lo primero sería delimitar que se entiende por calidad de vida, cuyo concepto es diferente según quien sea nuestro interlocutor, porque no es lo mismo la calidad de vida requerida en la sociedad del mundo occidental, que la que desean los habitantes del tercer mundo, para quienes satisfacer sus necesidades mínimas es ya un gran logro. Sin embargo, la calidad de vida que se requiere en la parte del mundo en que vivimos, pasa desde luego, por una alimentación sana y equilibrada, una escasa contaminación medio-ambiental, una buena educación que nos permita el acceso digno al mundo del trabajo y un tiempo libre para dedicar al ocio y a la actividad física que, como consecuencia, nos depararán una buena salud. En la medida en que seamos capaces de conseguir está calidad de vida sugerida, nuestra sociedad estará más y mejor desarrollada.

Como vemos, la actividad física vuelve a estar presente en la transversalidad ocupando, en alguna medida, el tiempo de ocio y, como es manifiesto y ya se ha dicho, que la sociedad occidental actual, dispone de más tiempo libre, goza de mejor salud y su esperanza de vida ha aumentado considerablemente, se puede incidir en cuestiones deportivo-recreativas, que favorezcan la socialización y permitan conservar un buen estado físico.

Por último, hemos de hacer alusión a la educación ética y moral, muy relacionada, en general, con la educación en valores. Su aplicación a través de la EF, consistirá en que alumnos y alumnas aprendan a respetar las normas en los deportes que se practiquen, evitando comportamientos pícaros, violentos o confusos, que pueden desencadenar frustraciones y estados emocionales no deseados. Respetar el medio ambiente, conociendo los problemas de especulación del suelo, incendios provocados y/o deterioro por realización de actividades físicas en la naturaleza que erosionan o dañan el terreno.

La cooperación y colaboración con sus compañeros, así como la participación con opiniones propias, reflexivas y críticas que podrán ser debatidas con el resto de la clase, permitirá que adquieran principios éticos y morales sólidos, que repercutirán en su futura vida de adultos.

\section{Conclusiones}

A lo largo de esta exposición, se han recorrido las corrientes de EF y Deporte como nuevas tendencias que han tenido mayor o menor influencia en la aplicación práctica de la materia durante muchos años, incidiendo en aquellas que actualmente empiezan a despuntar abriendo nuevas y mejores perspectivas laborales y sociales.

Hemos pasado de las corrientes basadas en modelos educativos más tradicionales, a las que demandan otros más innovadores; de las que defienden un modelo deportivo, a las que favorecen la expresión corporal excluyendo el deporte del currículum escolar y apoyando actividades lejanas al ámbito deportivo. Pero, por todos es conocido que tanto la práctica deportiva, como su contemplación, constituyen una de las más populares y extendidas formas contemporáneas de utilización del tiempo libre, además de ser la base de una poderosa industria de servicios.

Las corrientes descritas han dado lugar a distintos modelos de EF que permiten su utilización para alcanzar los diferentes fines que persigue, porque la EF, es probable- 
mente la materia del currículum escolar que mayor ayuda presta a la educación en el proceso de socialización, ya que, por una parte, el alumnado está normalmente más interesado por las actividades físicas que por las cognitivas $y$, a través de aquellas se puede conseguir el desarrollo de éstas y, por otra, la relación del profesorado con los alumnos y alumnas, es más directa, localizada en espacios abiertos, en los que se sitúa de forma interdiferenciada entre ellos, lo que le permite influir, de manera más clara, en su socialización y humanización.

Por otro lado, el Ilamado "culto al cuerpo" que practica la sociedad actual, en detrimento de lo que debería ser "cuidado del cuerpo", se produce por la presencia que la corporalidad tiene en la vida cotidiana, que viene marcada por la publicidad, vestuario, alimentación, deportes de riesgo y aventura, cuerpos fuertes en los varones y delgados en las mujeres, etc.., que han hecho que la imagen corporal adquiera dimensiones inusitadas en otras épocas, destacando dos conceptos implícitos en ella, belleza y salud.

Ante esta realidad, el área de EF, a través de los ejes transversales, recogidos en la LOGSE, debe acometer su aplicación docente partiendo de las palabras de Ausubel y col. (1983): "El factor más importante que influye en el aprendizaje es lo que el alumno ya sabe. Averigüese y actúese en consecuencia", en la consideración de que con la transversalidad se pretenden recoger en el currículum educativo aquellos aspectos de la vida en sociedad que, sin formar parte de un área determinada, están implícitos en todas y su aprendizaje es de vital importancia para la educación.

Comúnmente se acepta que las ventajas de la actividad física sobre la persona son la mejora de la función orgánica, de la mecánica corporal, de la línea del cuerpo, de la función mental, del aumento de la longevidad, y de la comunicación social. Pero la actividad física no es inamovible, sino que va cambiando en función de las modificaciones sociales que se van produciendo. Estas modificaciones se pueden resumir en las siguientes:

- El modelo recreativo ha sustituido al competitivo, al menos en edades tempranas y por supuesto en la tercera edad. El Deporte para Todos, en el último cuarto de siglo, ha convertido la participación recreativa en una expresión de la cultura de masas.

- Como resultado de la pluralidad de actividades físicas, las instalaciones han dejado de ser las tradicionales, ocupando el medio rural, natural y urbano un gran espectro del espacio en el que se realiza deporte y ejercicio.

- El carácter socializador de las actividades físicas es indiscutible, por ello, su fomento en edades superiores es aconsejable, dada la tendencia al retraimiento y la depresión que se produce en la tercera edad. Como consecuencia, el aumento de la autoestima y autoimagen, surgen de la práctica deportiva moderada en cualquier edad.

- Los hábitos deportivos creados en las edades más tempranas, permiten a muchos de los mayores continuar con asiduidad sus prácticas físicas, pero también, aqueIlos que no han realizado actividad física en su infancia, juventud y/o madurez, pueden acercarse a ella para beneficiarse de sus múltiples ventajas.

\section{Referencias bibliográficas}

ARNOLD, P.J. (1991) Educación Física, movimiento y currículum, Madrid, Morata.

ARTERO ORTA, P. y MOYA HERNANDO, E. (1992) Bases para la individualización del ejercicio. aspectos mecánicos y posturales. Relajación. En Medicina Deportiva en la tercera edad, Cuadernos técnicos del deporte, nº 19, Málaga, Unisport, pp. 141-163. 
AUSUBEL, D.P.; NOVAK, J.D.; HANESIAN, H. (1983) [in 1978] Psicología educativa, México, Trillas.

BARBERO DE ZUBílLAGA, M. (1999) Los tratamientos del futuro. En El Semanal, suplemento Diario Jaén, 26 diciembre 99, p. 62.

BARRIGA IBARS, C. y otros (1998) Deporte y salud: ejercicio y sistema inmune. En Revista Élide, Madrid, Anaya.

BLÁZQUEZ, D. (1993) Perspectivas de la evaluación de la Educación Física y deporte. En Apunts no 31, pp. 5-16, Barcelona, INEF.

BOE (1990). LOGSE (Ley de Ordenación General del Sistema Educativo), Ley Orgánica de 3/10/90. BOE no 238 de 4/10/90.

CAGigAl GutiérReZ, J.M. (1966) Deporte, Pedagogía y Humanismo, Madrid, Ramos artes gráficas.

CONTRERAS JORDÁN, O.R. (1996) Didáctica de la Educación Física. Componentes didácticos y núcleos de actividades de enseñanza-aprendizaje. En García Hoz, V. (Dir.), Personalización en la Educación Física. Madrid, Rialp, pp. 302-320.

CARLQUIST, M. y AMYLONG, T. (1973) Gimnasia Infantil, en busca del ritmo en la gimnasia, 3ạ Edición, Buenos Aires, Paidós.

CELORIO (1996) Desde una transversalidad de trámite a una transversalidad renovadora. En Aula de Educación, no 51, pp. 31-36.

CHINCHILLA, J.L. y ZAGALAZ, M.L. (1997) Educación Física y su Didáctica en Primaria. Torredonjimeno. Jabalcuz (Jaén).

COPEF, Serie Divulgación, no 1, pp. 12, 15, 28, 35 y 79.

COUBERTín, P. de (1922) Pedagogie sportive, París, G. Crès et Cie.

CUENCA CABEZA, M. (1999) La nueva autorrealización. El Semanal, suplemento Diario Jaén, 26-12-99, p. 82.

DEWARD, A. (1993) El cuerpo marcado por el género en educación física: una perspectiva feminista crítica. En Investigación alternativa en educación física, Málaga, UNISPORT.

DIEM, C. (1996) Historia de los Deportes. Vol. I, Barcelona, Luis de Caralt Editor.

DICCIONARIO DE LA LENGUA ESPAÑOLA DE LA REAL ACADEMIA (1956).

DUMASEDIER, J. y HENNION, R. (1960) Trabajo publicado en el Boletín Internacional de Servicios Sociales de la UNESCO, Diciembre.

GARCÍA, A.; MIGUEL, A.; ABARDÍA. F. (1992) Sobre los Ilamados "deportes alternativos", Perspectivas de la actividad física y el deporte, no 10, pp. 13-15.

GILLET, B. (1971) Historia del Deporte, Barcelona, Oikos-tau.

GONZÁLEZ, F. y NOVAK, J. (1993) Aprendizaje significativo. Técnicas y aplicaciones, Madrid, Cincel.

GRUPPE, O. (1976) Teoría Pedagógica de la EF. Madrid. INEF. 
GUTIÉRREZ CARDEÑOSA, S. (1998) El deporte como medio educativo. Actas al XVI Congreso Nacional de EF. de Facultades de C.C. de la Educación y Escuelas de Magisterio, Badajoz.

JAENES SÁNCHEZ, J.C. (1992) Características de un programa de la Tercera edad. En Medicina Deportiva en la tercera edad, Cuadernos técnicos del deporte, ํo 19, Málaga, Unisport, pp. 45-52.

JUNTA DE ANDALUCÍA (1988) Salud para todos 2000, Cuadernos de salud, Sevilla, Consejería de Salud y Servicios Sociales.

KNAPP, B. (1981) La habilidad en el deporte, Valladolid, Miñón.

LAGARDERA OTERO, F. (1992) Sobre aquello que puede educar la EF.. En Revista Interuniversitaria de Formación del Profesorado, no 15, Septiembre/diciembre, pp. 55-72.

LAPIÈRRE, A. y AUCOUNTURIER, B. (1977) Simbología del movimiento, Barcelona, Científico-médica.

LÓPEZ IBOR, J.J. (1966) Prólogo a la obra de Cagigal, J.M. (1966) Deporte, Pedagogía y Humanismo, Madrid, Ramos artes gráficas.

LOZANO, J.J. (1996). Ideas previas como punto de arranque de la Asignatura "Educación Física y su Didáctica I". En Actas del III Congreso Nacional de EF de Facultades de Educación y XIV de Escuelas de Magisterio, Guadalajara.

MARCOS BECERRO, J.F. (1995) Consideraciones sobre la acción del ejercicio y el deporte en el mantenimiento de la salud y en la prevención de la enfermedad. En Salud, ejercicio y deporte, Madrid, MAPFRE.

MARTÍN LLAUDES, N. (1992) Mantenimiento y mejora de las cualidades físicas en la tercera edad. En Medicina Deportiva en la tercera edad, Cuadernos técnicos del deporte, oo 19, Málaga, Unisport, pp. 97-119.

MAYER, O. (1962) A través de los aros Olímpicos. Madrid. Artes Gráficas Benzal.

MEC (1970) Ley General de Financiación y Reforma del Sistema Educativo, Madrid, Centro de Publicaciones del Ministerio.

MEC (1990) Ley Orgánica de Ordenación General del Sistema Educativo, Madrid, Centro de Publicaciones del Ministerio.

MEC (1992) DCB. Primaria. Área de Educación Física. Madrid.

MIRANDA, J. (1993). La postmodernidad y la actividad física. En Revista Perspectivas de la Actividad Física y el Deporte, no 13, pp. 36-41.

MUÑOZ SOLER, A. (1979) La acción deportiva (Psicología y psicopatología del deporte), Madrid, Ministerio de Cultura.

OLDENHOVE, H. (1992) El deporte, cosa de todos. En Actas del Congreso Científico Olímpico. IAD. Málaga. ㄲo 24- Vol. II.

OMS (1985) Metas de salud para todos, Copenhague, Oficina Regional para Europa.

PARLEBÁS, P. (1974) Activités physiques et éducation motrice, París, Editions Revue Education Physique et Sport. 
PIAGET, J. (1975) Psicología de la inteligencia, Buenos Aires, Psique.

PIERNAVIEJA DEL POZO, M. (1959) La Educación Física en España. Antecedentes histórico-legales, Madrid, C. Bermejo Impresor.

PIERNAVIEJA DEL POZO, M. (1967) Depuerto, Deporte: Protohistoria de una palabra, Madrid, INEF.

PUNSET, E. (1999) Apostar por la diversidad. En El Semanal, suplemento Diario Jaén, 26 diciembre, p. 42.

ROMERO RAMOS, O. y otro (1998) El ocio y la EF.. En Actas del XVI Congreso Nacional de EF. Facultades de CC de la Educación y Escuelas de Magisterio, Badajoz, pp. 255-260.

SEURÍN, P. (1949) Hacia una EF. Metódica, Burdeos, Bière.

SHILLING, C. (1993) Cuerpo, escolarización y teoría social: el capital físico y la política de enseñanza de la educación física. En II Encuentro sobre Investigación Alternativa en Educación Física, Málaga, Unisport.

SORIA, M.A. y CAÑELLAS, A. (1991) La animación deportiva, Barcelona, INDE.

ULMANN (1982) De la gymnastique aux les sports modernes, París, Urin.

VAYER, P. (1972) El diálogo corporal, Barcelona, Científico-médica.

VÁZQUEZ, B. (1989) La Educación Física en la Educación Básica, Madrid, Gymnos.

VÁZQUEZ, B. (1996) Educación Física y coeducación. En García Hoz, V. (Director), Personalización en Educación Física, Madrid, Rialp, pp. 321-336.

VILLANÚA, E. (1956) La EF. frente al problema sexual de la humanidad y valor biopsico-social de ella en las generaciones actuales. Actas del II Congreso Internacional Latino de EF, Madrid, junio.

VVAA (1985) Nueva Enciclopedia Larousse, Barcelona, Planeta.

YUS, R. (1996) Temas transversales: hacia una nueva escuela, Barcelona, Graus.

ZAMBRANA, J.M. (1985) Deporte para todos... los adultos, Madrid, Alhambra.

ZAGALAZ, M. L. (1996). La Educación Física Femenina en España, Jaén, Universidad de Jaén.

ZAGALAZ, M.L. (1999) Fundamentos legales de la actividad física en España, Jaén, Servicio de Publicaciones de la Universidad de Jaén.

ZAGALAZ, M.L. y CACHÓN, J. (1999) Sobre el concepto de educación física y deporte: teorías, aspectos y definiciones. En Sainz, P, y otros (Coords.) Actas del Congreso Nacional de Educación Física, celebrado en Huelva, Málaga, IAD, pp. 1.253-1.268. 